\title{
Icelandic community pharmacists' and pharmacy students' expectations of future role extensions and education requirements: A cross-sectional survey
}

\author{
Anita Elaine Weidmann ${ }^{1}$ (D) Unnur Karen Guðbjörnsdóttir ${ }^{2}$, Anna Ingibjorg Gunnarsdottir ${ }^{2}$ (D) Petur \\ Gunnarsson $^{2}$ iD Freyja Jónsdóttir ${ }^{2}$ iD \\ ${ }^{1}$ Robert Gordon University, School of Pharmacy and Life Sciences, Aberdeen, United Kingdom \\ 2University of Iceland, Faculty of Pharmaceutical Sciences, Reykjavik, Iceland
}

\section{Keywords}

Community pharmacy

Education

Iceland

Role extension

Training

\begin{abstract}
Aim: To explore the expectations of Icelandic community pharmacists and final year pharmacy students on future role extensions and associated education needs. Methods: All community pharmacists across Iceland registered with the Pharmaceutical Society of Iceland (LFI) ( $n=136)$ and all fourth- and fifth-year pharmacy students enrolled at the Faculty of Pharmaceutical Sciences at the University of Iceland $(n=69)$. An online cross-sectional questionnaire was designed, validated, piloted and analysed using descriptive statistics, logistic regression and content analysis. Results: The response rate was $27.9 \%(n=38)$ for community pharmacists and $33.3 \%(n=23)$ for fourth- and fifth-year pharmacy students respectively. Of these, $90.2 \% \quad(n=55)$ saw the need for community pharmacists' role extensions and most ( $n=60,98.4 \%$ ) were willing to accept additional education to make role extensions in Iceland possible. Logistic regression identified that students identified the need for pharmacists to be making prescribing recommendations to medical healthcare professionals ( $p=0.023$ ); for example "Pharmacists should use their knowledge to give advice and collaborate with physicians and other healthcare professionals about drug therapies". Conclusion: Both community pharmacists and pharmacy students showed a strong willingness to extend their roles in the future. It will require government support to overcome perceived barriers and to develop further education programmes.
\end{abstract}

\section{Introduction}

Never has the pivotal role of the community pharmacist in promoting healthier lifestyles, management of chronic medications, and disease prevention been more obvious than during the current COVID19 pandemic (Aldeyab, 2020). Due to their accessibility and wide geographical distribution, community pharmacies are often the first point of contact for people with health-related concerns. Therefore, they have an essential responsibility to ensure access to medicines and medical devices, contributing to effective medication management in both acute and chronic conditions and providing public health education (International Pharmaceutical Federation, 2020). While pharmacists, internationally, have seen an emergency extension of their authorised roles to reduce the need for medical appointments and a release of resources during the pandemic, pharmacists have been evolving to provide more clinically relevant services in a bid to support prescribed therapeutic treatment outcomes and the economical use of medication resources over the past two decades 
(Rawlins, 1991; Moltó-Puigmarti, 2018; Švarcaitè, 2019; Merks, 2020).

Although pharmacists are the third-largest group of healthcare professionals in the European Union (EU) after physicians and nurses, the development of a role extension has been very fractious with no clear, standardised policy across Europe (Garattini, 2020). As a result, community pharmacists' extended roles vary depending on the country they work in (Mossialos, 2015). Countries such as the United Kingdom, the Netherlands, and many countries outside Europe, such as Australia, Canada, and the United States (US), are examples where community pharmacists' roles have undergone a drastic change in the past two decades. In addition to the traditional roles, they provide more person-centred services such as medication reviews, independent prescribing and general health promotions. A role extension that is not reflected across all of the European countries is Iceland (Ministry of Welfare, 2012).

According to Icelandic legislation, a pharmacist is responsible for the administration of medicines as well as addressing drug-related problems (Blöndal, 2017). While clinical pharmacists conduct these roles in the hospital setting, community pharmacists' roles still mainly focus on dispensing medicine and short patient consultations (Ministry of Welfare, 2017; Blöndal, 2021). Blöndal et al. (2017) conducted a study aiming to introduce pharmacistled pharmaceutical care into primary healthcare clinics in collaboration with General Practitioners (GPs) in Iceland for the first time. In this study, a pharmacist worked closely with five GPs in the Reykjavik area. GPs referred selected patients over the age of 65 to the pharmacist for a medication review service, and any identified care issues were fed back to the GP for consideration (Ministry of Welfare, 2017). The results of this research showed that for each interviewed patient, the pharmacist found, on average, two drug-related problems, and the GP considered the pharmacists' comments in $90.3 \%$ ( $n=159)$ of cases. GPs' awareness about pharmacist competencies as healthcare providers and their potential role in patient care increased. Furthermore, GPs voiced a desire to have regular daily access to pharmacists in the future (Ministry of Welfare, 2017).

In a second study, this desire was confirmed as Icelandic GPs across 12 primary care practices in Iceland fully supported the notion that pharmacist-led clinical services could increase the quality of patient therapy (Blöndal, 2021). Improvement of communication between healthcare providers, clarifying pharmacists' specialist skill set and taking on more responsibilities while ensuring that they do not have a commercial conflict of interest were cited as essential factors to ensure a successful implementation of such a person-centred role extension.
In 2015, the Pharmaceutical Society of Iceland (LFI) and the Royal Pharmaceutical Society (RPS) in the UK signed a partnership to jointly work on foundation training (through University College London as a provider organisation) (Author unknown, 2015). The collaboration included an agreement to allow qualified Icelandic pharmacists with ten years of practice experience or more to complete the RPS Faculty assessment programme and implement the advanced training framework. Since then, 11 pharmacists have completed the RPS Faculty assessment for Advanced practitioners. Seven more pharmacists are presently undergoing foundation training, with a further four having already completed this successfully (Author unknown, 2018). This demonstrates that a structured further education programme for pharmacists in collaboration with other European training providers can successfully implement pharmacist role extension and patient care in Iceland.

While the attitudes and expectations of community pharmacists around the world with respect to their changing role extensions have been thoroughly explored in the published literature, it is less clear what final year pharmacy students' expectations are (Bell, 2001; Iversen, 2001; Bidwell, 2017). A survey collecting the views of final year pharmacy students in Jordan identified that students had an optimistic outlook about the future of the pharmacy profession. However, no details were given as to what this positivity related to (Mukattash, 2015). A study looking at the preparedness for practice of a group of 136 pharmacy intern students in Southern Australia, on the other hand, found that while pharmacy students felt prepared for many aspects of their job, there was a mismatch between expectations and actual experiences. By the end of their internship, almost half of the respondents intimated that they wanted to do something else other than being a practising pharmacist (Mak, 2013). While there is literature that focuses on the preparedness for practise of pharmacy students, there is a paucity of literature identifying the actual expectations of pharmacy students of their future role to ensure person-centred care.

Based on the global literature, there seems to be a clear ambition and interest to extend pharmacy roles in Iceland, especially in collaboration with the medical professions to promote patient care and safety across all sectors of pharmacy (Edmunds, 2001; Harrison, 2012; Horák, 2017). It is, however, unclear what community pharmacists' expectations of such role extensions are. As no previous studies have been conducted to explore Icelandic community pharmacists' or final year pharmacy students' views and expectations of such role extensions, this study aimed to explore expectations and establish education needs. 


\section{Aim of the study}

This study aimed to explore the needs and expectations of Icelandic community pharmacists and final year pharmacy students (MSc) on future role extensions and assess their associated education needs.

\section{Methods}

A pilot questionnaire was designed in accordance with published best practice and current scientific work conducted by the European Association of Hospital Pharmacists (EAHP) and reviewed for face and content validity by four research experienced pharmacy practitioners (Table I) (EAHP, 2010; Harrison, 2012). The pilot questionnaire comprised three sections containing a mixture of five-point Likert scale questions, closed questions and open response options. The questionnaire was translated into the Icelandic language, and crosslanguage checks were carried out independently by two researchers who are fluent in both languages before the pilot study (a copy in the Icelandic version is available upon request).

The pilot questionnaire included a cover letter describing the aim of the study and assurance of confidentiality. The online pilot questionnaire (Online Surveys [formerly Boston Online Services]) and invitation were emailed to 13 randomly selected community pharmacists across Iceland by the Pharmaceutical Society of Iceland (LFI), representing $10 \%$ of the final sample size $(n=136)$.

Table I. Overview of questions included in the online survey

\begin{tabular}{|c|c|}
\hline Section & Question topics included \\
\hline Background information & $\begin{array}{l}\text { - } \text { Gender } \\
\text { - } \text { Age } \\
\text { - } \text { Pharmacy position } \\
\text { - } \text { Years of experience } \\
\text { - } \quad \text { Experience of working as a practising pharmacist in another country } \\
\text { - } \quad \text { Country the original pharmacy degree was obtained in } \\
\text { - Employment status } \\
\text { - } \quad \text { Additional pharmacy qualifications }\end{array}$ \\
\hline $\begin{array}{l}\text { Role perception as a } \\
\text { community pharmacist }\end{array}$ & $\begin{array}{l}\text { - What would you consider to be a part of your role as a community pharmacist? } \\
\text { - Do you see a need for your role as a community pharmacist to extend in the next ten years, for example, to } \\
\text { include medication reviews, prescribing medicine, etc.? } \\
\text { - If yes, which additional roles do you think there is a need for? } \\
\text { - Why do you think it is important for community pharmacists in Iceland to extend their roles in the future? } \\
\text { - Have you heard of the extended roles community pharmacists have in other countries, for example, in the } \\
\text { - United Kingdom, Canada and The United States of America? } \\
\text { Please rate your agreement with the following questions: } \\
\text { - Community pharmacists' roles should stay as they are } \\
\text { - In the future, community pharmacists should be able to perform medication reviews for patients } \\
\text { - In the future, community pharmacists should be able to prescribe medicines independently } \\
\text { - In the fununity pharmacists should provide future services to promote better health and prevent } \\
\text { - In community pharmacists should have more of a patient advice role than dispensing } \\
\text { - I would like to extend my roles as a community pharmacist } \\
\text { - I think it would be difficult to induce these role extensions } \\
\text { - I am ready to take on extra training to be able to expand roles } \\
\text { - I think special remuneration should be applied for these role extensions } \\
\text { What do you think would be the most challenging part of extending the community pharmacists' role? }\end{array}$ \\
\hline Perceived training need & $\begin{array}{l}\text { - } \quad \text { Currently, is there any additional training you would welcome? } \\
\text { - What training do you think you would need in order to cope with extended roles such as medication reviews? } \\
\text { - What format should this training take to best suit you? } \\
\text { - How much time in total would you be willing to invest in this training? }\end{array}$ \\
\hline
\end{tabular}

Based on the small sample population of community pharmacists $(n=136)$ and fourth- and fifth-year pharmacy students $(n=69)$ across Iceland, the total population, were included using purposive sampling. No sample size calculation was required.

Participants included in the pilot were excluded from the final data collection phase. In addition to community pharmacists, the online pilot questionnaire was sent to six fourth- and fifth-year pharmacy students by the Faculty of Pharmaceutical Sciences at the University of Iceland, representing a total of $10 \%$ of the final sample size $(n=69)$. The pilot analysis resulted in no alterations to the wording of the questionnaire, and the results from the pilot study were included in the final analysis of the main data set. In March 2019, the LFI and the Faculty of Pharmaceutical Sciences sent the final online 
questionnaire survey to all community pharmacists $(n=136)$ and fourth- and fifth-year pharmacy students $(n=69)$. Two reminder emails were sent at two-weekly intervals.

Data were coded and entered into SPSS for Windows version 25 and analysed using descriptive statistics, logistic regression analysis $(p<0.05)$, reported as odds ratios (ORs) with $95 \%$ confidence intervals (Cls) to obtain an odds ratio when there is more than one explanatory variable and non-parametric statistical tests where appropriate (Fishers Exact test). Content analysis by two independent researchers was performed on the responses to open questions (Hsieh, 2005). Key themes are described using illustrative quotes, with each respondent assigned a number.

\section{Ethics approval}

This study was approved by the Ethical Review Panel of the School of Pharmacy and Life Sciences at Robert Gordon University, Aberdeen, UK and the Science Ethics Committee of the University of Iceland.

\section{Results}

A total of 38 questionnaires eligible for inclusion were returned by community pharmacists and 23 by pharmacy students, giving a response rate of $27.9 \%$ for community pharmacists and $33.3 \%$ for pharmacy students, respectively. Demographic data are detailed in Table II.

\section{Current roles of community pharmacists in Iceland}

Community pharmacists were asked to choose roles from a list they could most closely associate with in their current practice. All pharmacists $(n=38,100 \%)$ identified dispensing medication, providing advice to patients and the supply of products to relieve minor ailments as their roles. Almost all respondents $(n=37 ; 97.4 \%)$ also considered their roles to be formulation compounding, with two thirds ( $n=29 ; 76.3 \%$ ) considering the provision of medicines information to other healthcare professionals to be their role. Providing prescribing recommendations to medical professionals $(n=20,52.6 \%)$, providing regular medication reviews $(n=12,31.6 \%)$ and monitoring patient's conditions $(n=5,13.2 \%)$ were identified least often.

Logistic regression analysis identified that working in other countries $\left(p=0.07, \operatorname{Exp}(\mathrm{B})=23.25,95 \% \mathrm{Cl}^{*}=2.354-229.681\right)$; being a lead pharmacist $(p=0.028, \operatorname{Exp}(B)=20.667,95 \%$ $\left.\mathrm{Cl}^{*}=1.421-300.537\right)$ and having a postgraduate degree $(p=$
0.016, $\left.\operatorname{Exp}(B)=31,95 \% C l^{*}=1.896-506.771\right)$ were strong predictors of respondents considering the monitoring of a patient's condition to be part of their current role. Students were asked not to answer this question.

Table II. Demographic data

\begin{tabular}{|c|c|c|c|}
\hline Frequencies & & $\begin{array}{c}\text { Community } \\
\text { pharmacists } \\
(n=38) \\
n(\%)\end{array}$ & $\begin{array}{c}\text { Students } \\
\begin{array}{c}(n=23) \\
n(\%)\end{array}\end{array}$ \\
\hline \multirow[t]{2}{*}{ Gender } & Male & $16(42.1)$ & $7(30.4)$ \\
\hline & Female & 22 (57.9) & $16(69.6)$ \\
\hline \multirow[t]{10}{*}{ Age (years) } & $21-25$ & $1(2.6)$ & $19(82.6)$ \\
\hline & $26-30$ & $6(15.8)$ & $3(13.0)$ \\
\hline & $31-35$ & $7(18.4)$ & --- \\
\hline & $36-40$ & $6(15.8)$ & $1(4.3)$ \\
\hline & $41-45$ & $3(7.9)$ & --- \\
\hline & $46-50$ & $2(5.3)$ & --- \\
\hline & $51-55$ & $3(7.9)$ & --- \\
\hline & $56-60$ & $3(7.9)$ & --- \\
\hline & $61-65$ & $5(13.2)$ & --- \\
\hline & $66-70$ & $2(5.3)$ & --- \\
\hline \multirow{5}{*}{$\begin{array}{l}\text { Employment } \\
\text { status }\end{array}$} & Full time & $26(58.45)$ & --- \\
\hline & Part time & $9(23.7)$ & --- \\
\hline & Maternity leave & $2(5.3)$ & --- \\
\hline & Retired & $1(2.6)$ & --- \\
\hline & Other & --- & --- \\
\hline \multirow{2}{*}{$\begin{array}{l}\text { Completed } \\
\text { students' } \\
\text { fourth-year } \\
\text { training }\end{array}$} & Yes & -- & $17(73.9)$ \\
\hline & No & -- & $6(26.1)$ \\
\hline Years qualified & $0-2$ & $8(21.1)$ & --- \\
\hline \multirow{4}{*}{ as a pharmacist } & $3-5$ & $2(5.3)$ & --- \\
\hline & $6-10$ & 7 (18.4) & --- \\
\hline & $11-15$ & $3(7.9)$ & --- \\
\hline & More than 15 & $18(47.4)$ & --- \\
\hline \multirow{2}{*}{$\begin{array}{l}\text { Pharmacy } \\
\text { degree from } \\
\text { Iceland }\end{array}$} & Yes & 30 (78.9) & \\
\hline & No & $8(21.1)$ & \\
\hline \multirow{5}{*}{$\begin{array}{l}\text { Years as a } \\
\text { community } \\
\text { pharmacist }\end{array}$} & $0-2$ & $7(18.4)$ & --- \\
\hline & $3-5$ & $4(10.5)$ & --- \\
\hline & $6-10$ & $8(21.1)$ & --- \\
\hline & $11-15$ & $4(10.5)$ & --- \\
\hline & more than 15 & $15(39.5)$ & --- \\
\hline \multirow{2}{*}{$\begin{array}{l}\text { Previous work } \\
\text { in any other } \\
\text { sector of } \\
\text { pharmacy }\end{array}$} & Yes & $16(42.1)$ & \\
\hline & No & $22(57.9)$ & \\
\hline \multirow{2}{*}{$\begin{array}{l}\text { Worked in } \\
\text { countries other } \\
\text { than Iceland }\end{array}$} & Yes & $5(13.2)$ & --- \\
\hline & No & $33(86.8)$ & --- \\
\hline \multirow{7}{*}{$\begin{array}{l}\text { Postgraduate } \\
\text { degrees }\end{array}$} & PgCert/Dip/MSc in & --- & --- \\
\hline & $\begin{array}{l}\text { Clinical Pharmacy } \\
\text { Service }\end{array}$ & & \\
\hline & $\begin{array}{l}\text { PgCert/Dip/MSc in } \\
\text { Advanced } \\
\text { Pharmacy Practice }\end{array}$ & --- & --- \\
\hline & $\mathrm{PhD}$ & $1(2.6)$ & --- \\
\hline & PharmD & --- & \\
\hline & $\begin{array}{l}\text { No postgraduate } \\
\text { degree }\end{array}$ & $32(84.2)$ & \\
\hline & Other & $3(7.9)$ & \\
\hline
\end{tabular}

\footnotetext{
" Confidence intervals (Cis) with inclusion of sample outliers
} 


\section{Perceived future roles of community pharmacists in Iceland}

A large majority of respondents (community pharmacist $n=32 ; 84.2 \%$; students $n=23 ; 100 \%$ ) saw a need for their future role as community pharmacists to extend in the next ten years. Only three community pharmacists (7.9\%) disagreed, with a further three remaining undecideds (7.9\%).

Figure 1 illustrates that community pharmacists considered the provision of regular medication reviews ( $n=30 ; 78.9 \%)$, pharmacist prescribing ( $n=29 ; 76.3 \%)$, and the provision of a chronic medication service $(n=24 ; 63.1 \%)$ to be their most desired future roles. Formulation compounding $(n=11$; $28.9 \%$ ) and the provision of home visits to patients who are unable to come to the pharmacy $(n=9 ; 23.7 \%)$ were found to be the least desirable future roles. On the other hand, students were generally more enthusiastic when it came to providing services as part of their future roles, with $61 \%$ $(n=8)$ of services ranking of almost equal importance. These include but are not limited to the provision of advice to medical and other healthcare professionals ( $n=17 ; 73.9 \%)$; monitoring of patient's condition ( $n=18 ; 78 \%$ ); provision of medicines information to other healthcare professionals ( $n=18$; 78\%); making prescribing recommendations to physicians ( $n=18 ; 78 \%$ ); services to nursing homes ( $n=17$; $73.9 \%)$ and the provision of public health advice $(n=17$; 73.9\%). Almost all students, however, expect to provide regular medication reviews $(n=22 ; 95.6 \%)$. The least desirable expectation selected by students were formulation compounding $(n=5 ; 21.7 \%)$ and smoking cessation clinics $(n=5 ; 21.7 \%)$. This was reflected in their open comments.

"Pharmacists should use their knowledge to give advice and collaborate with physicians and other healthcare professionals about drug therapies, to ensure that patients get the right treatment, especially (for) polypharmacy patients." (P-11)

"The community pharmacy has an important role in healthcare services. It is one of the most visited healthcare system destinations where patients have the best access to expert knowledge about their medications. Additional collaboration between community pharmacists and other healthcare professionals (..) can have a lot of benefits (...). Additional medication therapy follow-up can lead to faster interventions and better medication adherence. (...) to give patients a more personal, individual and targeted service." (P-28)

Logistic regression identified that students saw the need for pharmacists to be making prescribing recommendations to medical healthcare professionals $(p=0.023 \operatorname{Exp}(B)=4.5,95 \%$ $\left.\mathrm{Cl}^{*}=1.228-16.486\right)$, but saw less of a future need to become independent prescribers $\left(p=0.014, \operatorname{Exp}(\mathrm{B})=0.160,95 \% \mathrm{Cl}^{*}=\right.$ $0.037-0.694)$. This opinion was in direct contradiction to currently practicing community pharmacists who felt strongly about the need to become an independent prescriber in the future $\left(p=0.014 \operatorname{Exp}(\mathrm{B})=6.23195 \% \mathrm{Cl}^{*}=\right.$ 1.440-26.953) but felt less strongly about extending their role to making prescribing recommendations to the prescriber $\left(p=0.023 \operatorname{Exp}(\mathrm{B})=0.22295 \% \mathrm{Cl}^{*}=0.061-0.814\right)$.

\section{Perceived barriers for extending community pharmacists roles in Iceland}

While the majority of respondents agreed or strongly agreed $(n=51 ; 83.6 \%)$ that such role extensions are feasible, the respondents also identified several barriers they felt had to overcome, including: availability of staff resources $(n=16$; $26.2 \%)$; availability of time resources $(n=4 ; 6.6 \%)$; additional cost of implementation of services ( $n=13 ; 21.3 \%)$; remuneration of services $(n=8 ; 13.1 \%)$; the attitude towards the pharmacy profession $(n=7 ; 11.5 \%)$; the attitude of community pharmacists towards these role extension $(n=3$; $4.9 \%)$ and insufficient education and training ( $n=5 ; 8.2 \%)$.

"This is all a question of money, staffing and environment. The exemption of the 'two pharmacists' rule' has to be abolished in many pharmacies. A pharmacist can give limited advice when he is the only pharmacist present. The government has to bring in funding if the roles should extend." (P-33)

"Every change that is worth doing is difficult. Community pharmacists' role extensions (...) requires a lot of planning and overview (...). I cannot foresee any problems with patients or employees since by my own experience there seems to be a will from both groups to add to the pharmacy's roles within the healthcare professions." (P-28)

\section{Perceived training needs to meet the demands of the identified extended roles}

Almost half of the surveyed community pharmacists ( $n=17$; $44.7 \%)$ and pharmacy students $(n=5 ; 21.7 \%)]$ chose not to answer the question on perceived additional training need. Of those who did answer, the majority would welcome additional training opportunities, namely community pharmacists ( $n=16 ; 42.1 \%$ ) and pharmacy students ( $n=11$; $47.8 \%)$ ]. In an open response, the following additional training needs to meet future role extension requirements were identified: Communication skills (with both physicians and patients); performing medication reviews; drug interactions and the use of drug interaction databases as well as clinical pharmacy and the management of special therapeutic patient groups.

\footnotetext{
${ }^{*}$ Confidence intervals (Cis) with inclusion of sample outliers
} 


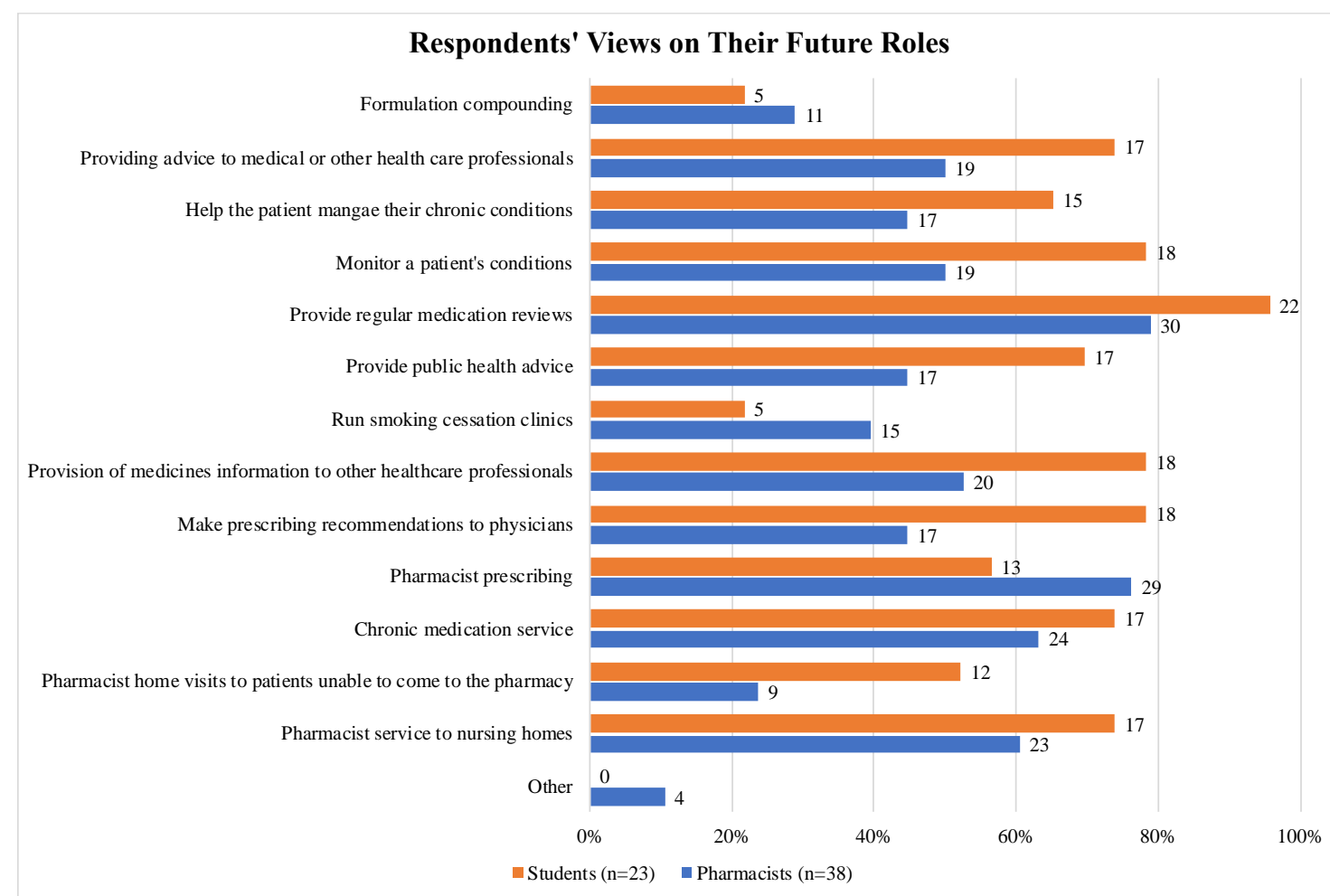

Figure 1. Community pharmacists and students' expectations of their future roles

\section{Format and extent of desired additional training}

Table III shows that the majority of respondents (community pharmacists ( $\mathrm{n}=20 ; 52.6 \%)$; pharmacy students ( $n=14 ; 60.9 \%)$ ) would prefer face-to-face workshops or seminars; while fewer considered online webinars (community pharmacists $(n=9 ; 23.7 \%)$; pharmacy students $(n=4 ; 17.4 \%))$. There was some willingness to complete an additional postgraduate degree such as Postgraduate Certificate (PG Cert) / Postgraduate Diploma (PG Dip/Master (MSc) in clinical pharmacy (community pharmacists ( $n=3 ; 7.9 \%)$; pharmacy students $(n=3 ; 13.0 \%))$. In the open comments, community pharmacists seemed to suggest that more clinical training needs to be provided in the undergraduate curriculum.

\begin{abstract}
"More targeted education and training, short seminars do not leave much behind. Medication reviews could be a speciality within the master's degree. The specialisation after the Bachelor (BSC.) degree has to be increased, nobody is able to do everything, and no one is especially good at anything. " $(P-52)$ '
\end{abstract}

"Focus on lengthening and adding to the practical courses at the hospital. Maybe even start sooner, not just in the MSc studies." (P-33)

This was also reflected in the willingness of the majority of respondents to invest more than 20 additional training hours (community pharmacists $(n=19 ; 50 \%$ ); pharmacy students ( $n=12 ; 52.2 \%)$ ). Cross-tabulations and logistic regression showed no significant demographic patterns associated with the willingness to complete extra training.

Table III. Preferred format of additional training opportunities

\begin{tabular}{|c|c|c|}
\hline Training format & $\begin{array}{c}\text { Community } \\
\text { pharmacists } \\
(n=38) \\
n(\%)\end{array}$ & 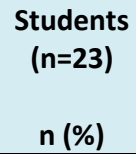 \\
\hline $\begin{array}{l}\text { Online training packages } \\
\text { and } M C Q \text { assessment }\end{array}$ & $3(7.9)$ & $0(0)$ \\
\hline $\begin{array}{l}\text { Face to face workshops or } \\
\text { seminars }\end{array}$ & $20(52.6)$ & $14(60.9)$ \\
\hline Webinars & $9(23.7)$ & $4(17.45)$ \\
\hline $\begin{array}{l}\text { Paper pack to work } \\
\text { through }\end{array}$ & $1(2.9)$ & $0(0)$ \\
\hline $\begin{array}{l}\text { Post graduate education } \\
\text { (e.g. PgCert/Dip/MSc in } \\
\text { clinical pharmacy) }\end{array}$ & $3(7.9)$ & $3(13.0)$ \\
\hline No answer & $2(5.3)$ & $2(8.7)$ \\
\hline \multicolumn{3}{|l|}{ Training extent } \\
\hline $0-5 h$ & $2(5.3)$ & $0(0)$ \\
\hline $6-10 h$ & $1(2.6)$ & $1(4.35)$ \\
\hline $11-15 h$ & $6(15.8)$ & $5(21.7)$ \\
\hline $16-20 h$ & $5(13.2)$ & $3(13.0)$ \\
\hline$>20 h$ & $19(50)$ & $12(52.25)$ \\
\hline None & $1(2,6)$ & $0(0)$ \\
\hline Not applicable & $4(13.2)$ & $2(8.7)$ \\
\hline
\end{tabular}




\section{Discussion}

There seems to be a great deal of optimism among community pharmacists and pharmacy students in Iceland, the majority of whom can see a need for their role to extend over the next ten years. The focus of these extensions centre on the provision of more personcentred services such as regular medication reviews, chronic medication services and, to some extent, pharmacist prescribing.

Almost all Icelandic pharmacy student respondents expect to be providing regular medication reviews in the future and see their role in providing prescribing recommendations and advice to medical healthcare professionals, with pharmacist prescribing being less of a priority for them. While some do not always welcome additional training opportunities, half of the respondents (both community pharmacists and students) are willing to invest more than 20 hours of additional training time as long as this is for the right type of face-to-face teaching. Common practice barriers identified by Icelandic community pharmacists, such as the need to recruit more staff in pharmacies, and time and financial resources, provide a clear expectation for the government to provide the funding to facilitate the success of these role extensions in the future. While the challenges of change are recognised, they are considered worth pursuing by Icelandic community pharmacists.

The optimistic expectation of present and future Icelandic community pharmacists to be providing more person-centred services reflects their understanding of the increased demand for health services in response to an ever-ageing population and a resultant increase in patients living with chronic conditions (Sigurgeirsdóttir, 2014). According to Statistics Iceland, $20 \%$ of the population will be older than 65 years by 2039, rising to over $25 \%$ by 2057 (Statistics Iceland, 2018). While this prediction means that the Icelandic population is and will be younger than the population average of most European countries, the average life expectancy is among the highest in the world (Statistics Iceland, 2018). The resultant increase in the number of patients living with chronic diseases and multiple comorbidities and the challenge of $25 \%$ of this population living in isolated communities increases the demand for healthcare services. In 2010, about $32 \%$ of GPs were aged 55 years and over, meaning that a third of the workforce is due to retire, posing concern over future recruitment and primary care service access. In fact, in some rural areas, GP posts have already been vacant for five to ten years. There is a need to steer the patterns of healthcare to prioritise primary care as the first port of call for patients in Iceland (Kringos, 2015). The openness of community pharmacists and pharmacy students towards such role extensions demonstrated in this study complements the notion of Icelandic GPs across several primary care practices that pharmacist-led clinical services can increase the quality of patient therapy (Blöndal, 2017; Blöndal, 2021).

While the issue of resource requirements, costeffectiveness and the impact of such role extensions on reducing healthcare costs is frequently raised, a recent systematic review by Dalton and Byrne (2017) concluded that while the review demonstrates that pharmacists can contribute to substantial healthcare savings across a variety of settings, there is a paucity of good quality economic evaluations of such services to date (Dalton, 2017). Aside from these resource-related barriers, the attitude towards the pharmacy profession and community pharmacists' attitude towards these role extensions were identified as potential barriers to pharmacists' role changes (Edmunds, 2001; Rosenthal, 2011). The Self-Efficacy model posits that self-efficacy is important in changing behaviour (Bandura A, 1986). Pharmacists require facilitation, guidance, and a model of practice that they believe they can adopt to participate in the change process. Similarly, they must be involved in multi-professional education to work in teams (Rosen, 2018). This is in line with some of the open comments in this study, in which both student and community pharmacists clearly see the need for more targeted education and training with an increased specialisation after the MSc degree and extended practice-based learning opportunities with interdisciplinary colleagues in the hospital setting. This highlights the need for structured further education opportunities that are designed specifically for community pharmacists working in the Icelandic healthcare context. Opportunities that participants in this study are more than willing to invest in are currently not yet available.

The Transtheoretical Model of behaviour change identifies a set of processes of change that move an individual from a pre-contemplative stage to an action stage (Prochaska, 2015). It provides a basic framework to describe six stages of behaviour change and is often used to plan and execute changes in healthcare practice (Taylor, 2006). In order to move a person towards considering change, strategies to increase awareness through providing information and education, experiencing different roles and reflection are needed. It could be argued that good quality further education opportunities and opportunities to understand better the skill sets needed to achieve the role extensions of community pharmacists as demonstrated in other countries is imperative to develop professional role extensions in Iceland successfully. Logistic regression analysis in this study has shown that overseas work experience, taking on a lead management role, and 
having completed a postgraduate degree were independent predictors of community pharmacists considering monitoring a patient's condition to be part of their current role. It would also explain why final-year pharmacy students fully expect to provide regular medication reviews as part of their daily practice and why they see the need to make prescribing recommendations to medical healthcare professionals because reflective practice and internationalisation are increasingly taught at the undergraduate level. This clearly evidences that good quality further education opportunities and opportunities to extend their skill set are imperative if a role extension among community pharmacists in Iceland is implemented successfully.

The recent COVID-19 pandemic has resulted in an acceleration of role extension for community pharmacists in many countries around the world. Reported role extensions include the eligibility to renew chronic treatment prescriptions, vaccine administration, facilitation of virtual medical consultations, eprescriptions, home drug delivery and mitigation of drug shortages (Merks, 2020). The aim is to utilise the limited healthcare resources effectively to prevent the healthcare systems from becoming overloaded (Merks, 2020). There is enormous potential for community pharmacies to manage conditions that double as risk factors for pandemic diseases in the future, including hypertension, respiratory system disease and cardiovascular diseases (Aldeyab, 2020). This opportunity for community pharmacies to become a hub for public health services is outlined in the Vision of the Department of Health and Public Health England (HM Government \& Department of Health, 2008; Public Health England, 2017). Role extensions in Iceland have not yet been reported.

To our knowledge, this is the first national study of its kind in Iceland. The study provides useful insights into community pharmacist expectations which is important for informing any political and professional discussions around developing role extensions in Iceland. However, the response rate across both populations is low, limiting the reliability and generalisability of results as nonrespondent bias could not be eliminated. It may be reasonable to assume that pharmacists without any interest in role extensions were less likely to participate. Further, the self-reported nature of the survey does not allow verification of the responses. It provides a very limited depth of data. A robust and well-designed qualitative interview study is recommended to verify these survey results and provide more in-depth information about the reasons behind role expectations present and future population groups. The two populations under study are challenging to compare and must be interpreted as two separate population groups, limiting the generalisability of the study results further.

\section{Conclusion}

This cross-sectional survey identified a considerable optimism among community pharmacists and pharmacy students in Iceland towards future role extensions to include more person-centred services. Government support will be needed to provide a structured training program and to overcome identified barriers. Community pharmacists and students across Iceland are setting a clear signal that they are ready and willing to develop primary care roles to support the quality of patient care in Iceland.

\section{Funding acknowledgement}

This research was carried out as part of an ERASMUS funded scholarship.

\section{References}

Aldeyab M., \& Al-Azzam S (2020). Community pharmacy has a big role in managing the conditions that double as risk factors for pandemic diseases. The Pharmaceutical Journal. Available at: https://pharmaceutical-journal.com/article/letters/communitypharmacy-has-a-big-role-in-managing-the-conditions-thatdouble-as-risk-factors-for-pandemic-diseases

Author unknown (2015). RPS signs international agreement to share best pharmacy practice. Available at: https://www.pharmaceutical-journal.com/your-rps/rps-signsinternational-agreements-to-share-best-pharmacypractice/20069513.article?firstPass=false

Author unknown (2018). Icelandic pharmacists receive Faculty pins at FIP 2018. Available at: https://www.pharmaceuticaljournal.com/news-and-analysis/news/icelandic-pharmacistsreceive-faculty-pins-at-fip2018/20205397.article?firstPass=false

Bandura A (1986). Social foundations of thought and action: A social cognitive theory. Englewood Cliffs, NJ: Prentice-Hall

Bell, H.M., Maguire, T.A., Adair, C.G., \& McGartland, L.F. (2001). Perceptions of CPD within the pharmacy profession. The International Journal of Pharmacy Practice, 9(S1), 55-55. https://doi.org/10.1111/j.2042-7174.2001.tb01115.x

Bidwell, S., \& Lee, T. (2015). GPs, community pharmacists and shifting professional boundaries. The New Zealand Medical Journal. 128(1414), 19

Blöndal, A.B., Sporrong, S.K., \& Almarsdottir, A.B. (2017). Introducing pharmaceutical care to primary care in Iceland-An action research study. Pharmacy. 5(2), 23. https://doi.org/10.3390/pharmacy5020023

Blöndal, A.B., Almarsdóttir, A.B., Jónsson, J.S., \& Gizurarson, S. (2021). General practitioners' perceptions of the current status and pharmacists' contribution to primary care in Iceland. International Journal of Clinical Pharmacy. 39(4), 945-952. https://doi.org/10.1007/s11096-017-0478-7 
Dalton, K., Byrne, S. (2017). Role of the pharmacist in reducing healthcare costs: current insights. Integrated pharmacy research \& practice. 6, 37-46. https://doi.org/10.2147/IPRP.S108047

Edmunds, J., \& Calnan, M.W. (2001). The reprofessionalisation of community pharmacy? An exploration of attitudes to extended roles for community pharmacists amongst pharmacists and General Practioners in the United Kingdom. Social Science \& Medicine. 53(7), 943-955. https://doi.org/10.1016/s02779536(00)00393-2

EAHP. European Hospital Pharmacy Survey 2010. Available at: https://www.eahp.eu/sites/default/files/files/EAHP\%20Survey $\% 202010(1) . p d f$

Garattini, L. (2020). Do European pharmacists really have to trespass on medicine? The European Journal of Health Economics. 22,1-4. https://doi.org/10.1007/s10198-020-01185$\underline{\mathrm{w}}$

Harrison, J., Scahill, S., \& Sheridan, J. (2012). New Zealand pharmacists' alignment with their professional body's vision for the future. Research in Social and Administrative Pharmacy. 8(1), 17-35. https://doi.org/10.1016/i.sapharm.2010.12.001

HM Government \& Department of Health. Pharmacy in England: Building on strength - delivering the future.(2008). Available at: https://assets.publishing.service.gov.uk/government/uploads/s ystem/uploads/attachment data/file/228858/7341.pdf

Horák, P., Gibbsons, N., Sýkora, J., Peppard, J., Gala, T.M., \& Underhill, J. (2017). EAHP European Statements Survey Results 2015. European Journal of Hospital Pharmacists. 24(3),138-146

Hsieh, H.E., \& Shannon, S.E. (2005). Three approaches to qualitative content analysis. Qualitative Health Research. 15(9), 1277-88. https://doi.org/10.1177/1049732305276687

International Pharmaceutical Federation (2020). FIP Health Advisory COVID 19: Guidelines for pharmacists and the pharmacy workforce. Available at: https://www.fip.org/file/4729

Iversen, L., Mollison, J., \& Macleod, T.N.N. (2001). Attitudes of the general public to the expanding role of community pharmacist: a pilot study. Family Practice. 18(5), 534 - 536. https://doi.org/10.1093/fampra/18.5.534

Kringos, D.S., Boerma W.G.W., Hutchinson, A., \& Saltman, B. (2015). Building primary care in a changing Europe: Case studies. Available at: https://www.ncbi.nlm.nih.gov/books/NBK459020/

Mak, V.S.L., March, G., Clark, A., \& Gilbert, A.L. (2013). Australian intern pharmacists' perceived preparedness for practice, and their expectations and experiences of the internship year and future career intentions. Integrated Pharmacy Research and Practice. 2013(2), 25-34

Merks, P., Jakubowska M., Drelich E., Swieczkowski D., Bogusz J., Bilmin K., Fehir Sola K., May A., Majchrowska A., Koziol M., Pawlikowski J., Jaguszewski M., \& Vaillancourt R. (2020). The legal extension of the role of pharmacists in light of the COVID-19 global pandemic. Research in Social and Administrative Pharmacy. 17(1),1807-1812. https://doi.org/10.1016/i.sapharm.2020.05.033

Ministry of Welfare (2012). Reglugerð um menntun, réttindi og skyldur lyfjafræðinga ogskilyrði til að hljóta starfsleyfi og sérfræðileyfi. Available http://www.reglugerd.is/reglugerdir/eftirraduneytum/velfe rdarraduneyti/nr/18543
Ministry of Welfare (2017). Reglugerð um lyfjaávísanir og afhendingu lyfja. Available at: http://www.reglugerd.is/reglugerdir/eftirraduneytum/velferdarraduneyti/nr/20867

Moltó-Puigmarti, C. (2018). A logic model for pharmaceutical care. Journal of Health Services Research \& Policy. 23(3), 148 157. https://doi.org/10.1177/1355819618768343

Mossialos, E., Courtin, E., Naci, H., Benrimoj, S., Bouvy, M., Farris, K., \& Sketris, I. (2015). From "retailers" to health care providers: Transforming the role of community pharmacists in chronic disease management. Health Policy. 119(5), 628-639. https://doi.org/10.1016/i.healthpol.2015.02.007

Mukattash, T.L., Nuseir, K.Q., Bilmji, E., Jarah, A.S., \& Alefin, Q. (2015). Students' perceptions of pharmacy as a specialisation and their future career, a cross section study of final year pharmacy students in Jordan. Jordan Journal of Pharmaceutical Sciences. 8 (8)

Prochaska, J.O., \& DiClemente C.O. (2015). The transtheoretical approach. In: Norcorss J.C. and Goldfried, M.r. (2nd Edition) Handbook of Psychotherapy Integration (p 147). Oxford University Press

Public Health England (2017). Pharmacy: A way forward for public health. Available at: https://assets.publishing.service.gov.uk/government/uploads/s ystem/uploads/attachment data/file/643520/Pharmacy a wa $\mathrm{y}$ forward for public health.pdf

Rawlins, M.D. (1991). Extending the role of the community pharmacist. British Medical Journal. 302,427-428

Rosen, M.A., DiazGranados, D., Dietz, A.S., Benishek, L.E., Thompson, D., Pronovost, P.J., \& Weaver, S.J. (2018). Teamwork in healthcare: key discoveries enabling safer, high-quality care. American Psychological Association. 73(4),433-450. https://doi.org/10.1037/amp0000298

Rosenthal, M.M., Breault, R.R., Austin, Z., \& Tsuyuki, R.T. (2011). Pharmacists' self-perception of their professional role: Insight into community pharmacy culture. Journal of the American Pharmacists Association. 51(3), 363-367. https://doi.org/10.1331/JAPhA.2011.10034

Sigurgeirsdóttir, S. Waagfjöd, J., \& Maresso. A. (2014). Iceland: Health system review. Health System in Transition. 16(6), 1-182,

Statistics Iceland (2018). Inhabitants in Iceland will be 436 in 2067. Available at: https://statice.is/publications/newsarchive/inhabitants/population-projections-2018-2067/

Švarcaitė, J. (2019). Ovierview of Community Pharamcy Services in Europe. Available at: www.oecd.org/els/health-systems/Item2b-Overview-Community-Pharmacy-Services-Svarcaite\%20.pdf

Taylor, D., Bury, PM., Campling, N., Carter, S., Garfield, S. Newbound, J., \& Rennie, T. N. (2006). A review of the use of the Health belief Model (HBM), the Theory of reasoned Action (TRA), the Theory of Planned behaviour (TPB) and the Trans-Theoretical Model (TTM) to study and predict health related behaviour change. National Institute of Clinical Excellence. Available at: https://www.nice.org.uk/guidance/ph6/resources/behaviourchange-taylor-et-al-models-review2 